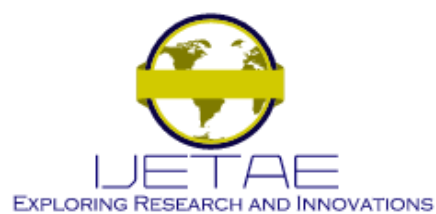

International Journal of Emerging Technology and Advanced Engineering

Website: www.ijetae.com (ISSN 2250-2459, ISO 9001:2008 Certified Journal, Volume 4, Issue 6, June 2014)

\title{
Image Analysis and Processing
}

\author{
Shashank Soi \\ B.Tech, Electronics and Communication Engineering, NIT Jalandhar
}

\begin{abstract}
This paper develops a base for the analysis and processing of the images. Image processing and analysis is an important aspect in the field of engineering and had attracted some of the brilliant minds from around the world in the past few years. The goal of this paper is to implement some of the fundamental techniques depicting the applications of image processing. The results of these techniques are verified by performing the simulations in MATLAB.
\end{abstract}

Keywords - Canny, DBM, Detection, Enhancement, MRI, Otsu's, Restoration, Segmentation.

\section{INTRODUCTION}

Image Processing is the study of techniques that takes image as the input, performs various measurements on the image and gives the processed image as output. Image processing techniques includes: a) Image editing and manipulation, b) Image enhancement, c) Feature detection, d) Image Compression, etc..

\section{AREAS INVOLVING IMAGE PROCESSING APPLICATIONS}

A. Astronomy:

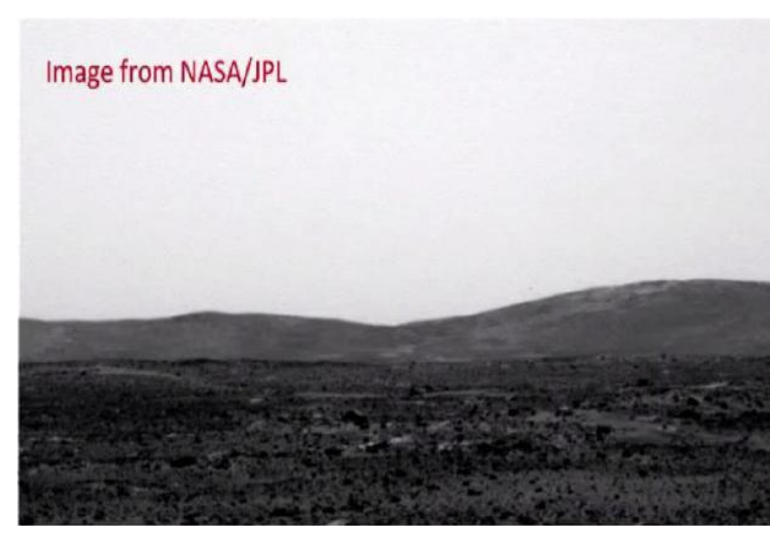

Fig 1. Mars Expedition

Fig1. shows the image of the surface of the mars taken by the NASA/JPL during the expedition of the mars.

\section{B. Biology:}

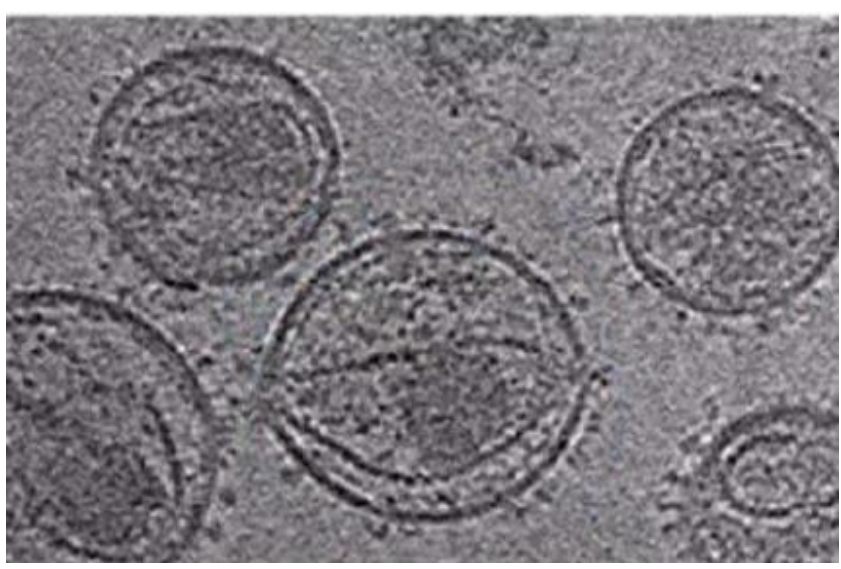

Fig 2. Envelope of HIV Virus

Fig. 2 shows the envelopes of various HIV Viruses. The image is the result of the image processing techniques applied to the microscopic images of the viruses.

C. Medicine:

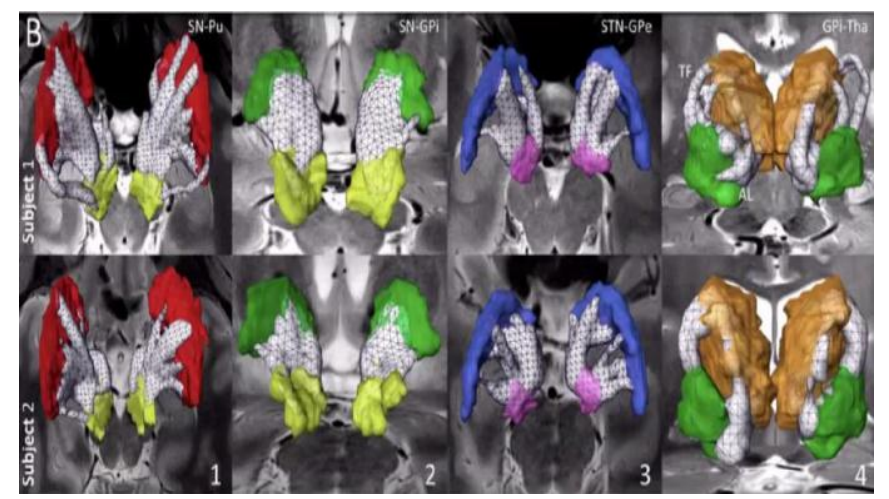

Fig 3. Specific White Matter Pathways

Fig 3 depicts the internal images of the brain with the image processing applied to it to detect the specific white matter pathways inside a brain. 


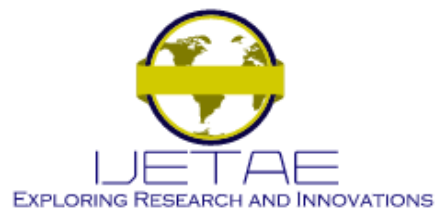

\section{International Journal of Emerging Technology and Advanced Engineering}

Website: www.ijetae.com (ISSN 2250-2459, ISO 9001:2008 Certified Journal, Volume 4, Issue 6, June 2014)

D. Security Purposes like Finger Print Scanning:

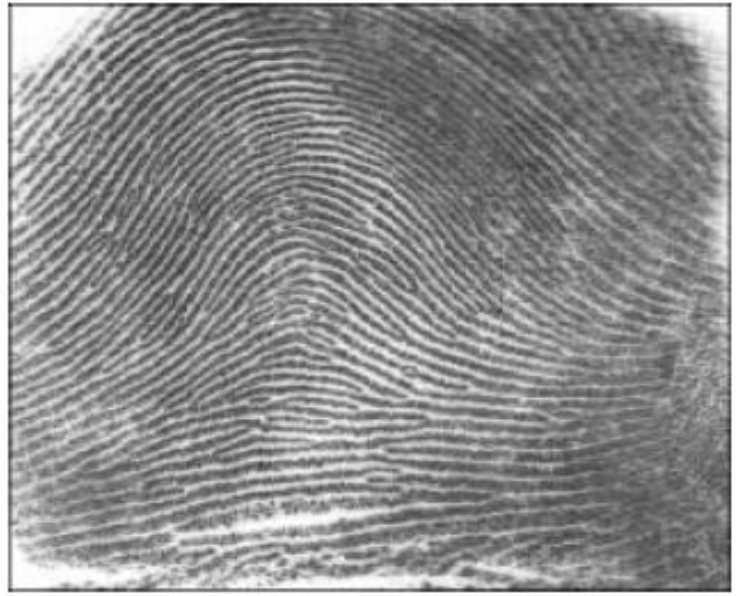

Fig 4. Scanned Image of fingerprints

E. Satellite Imaging of hurricanes, cyclones etc.:

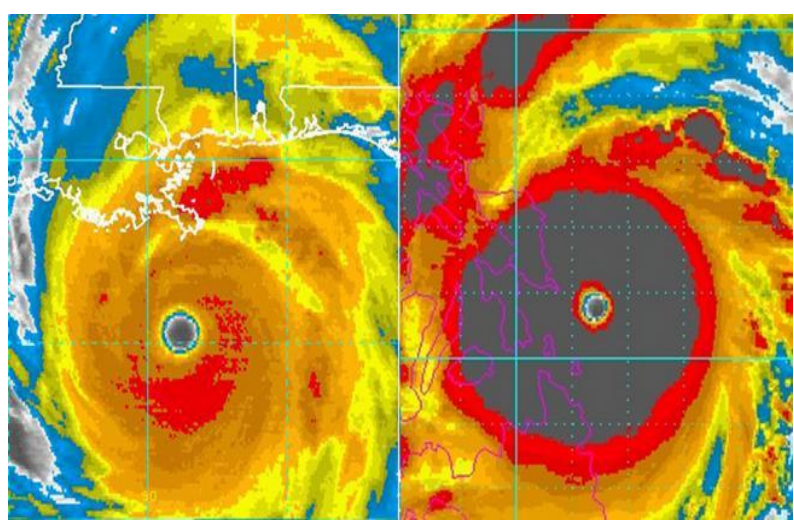

Fig 4. Cyclone Katrina (left) and typhoon Haiyan (right)

The above images of Fig 4 depict the intensities of these tropical storms. Redder colour indicates the coldness surrounding the regions.

\section{SIMPLE IMAGE PROCESSING OPERATIONS}

\section{A. Image Enhancement:}

Image enhancement improves the perceptibility of the image by modifying the brightness differences between the image and its background and suitably modifying other characteristics. To depict image enhancement a simple image of a camera man is taken (Fig 6) and the plot of the intensities in the image is plotted in form of a histogram (Fig 7).
As the image is quiet sharp and not clear hence the pixel values of the image is flipped over to obtain a better image (Fig 8) and the corresponding intensity plot is shown in (Fig 9). Comparing Fig 7 and Fig 9 we can easily see the flipped over pixel values.

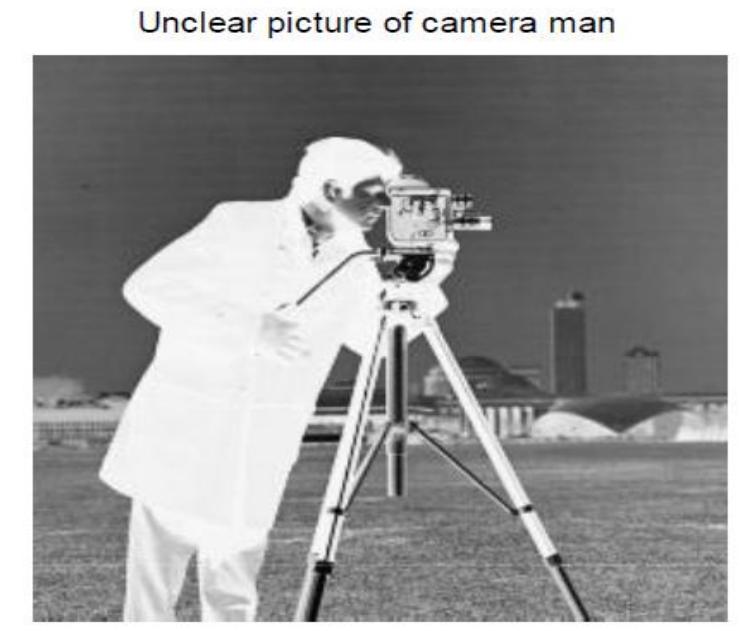

Fig 6. An image not good to view at

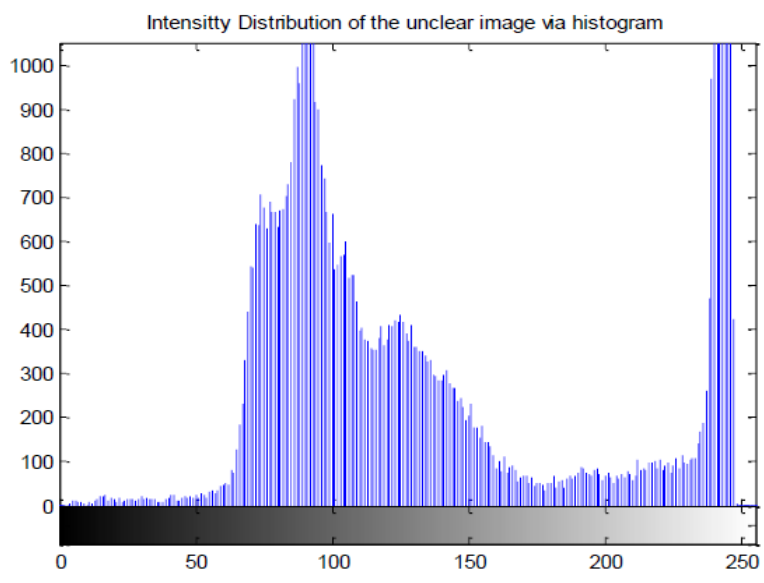

Fig 7. Histogram Plot of imafe of Fig 6 


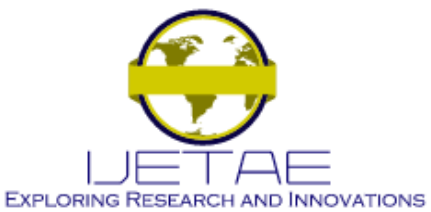

International Journal of Emerging Technology and Advanced Engineering

Website: www.ijetae.com (ISSN 2250-2459, ISO 9001:2008 Certified Journal, Volume 4, Issue 6, June 2014)

\section{Enhanced image of the camera man}

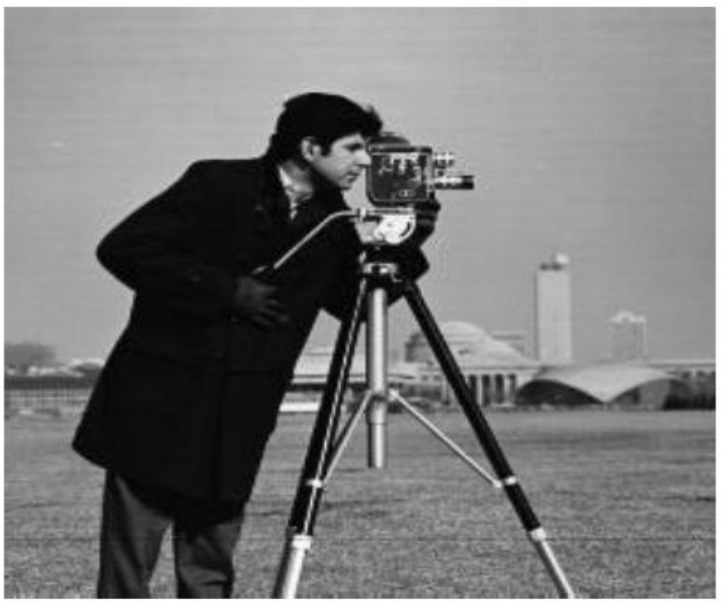

Fig 8. Improved image after enhancement

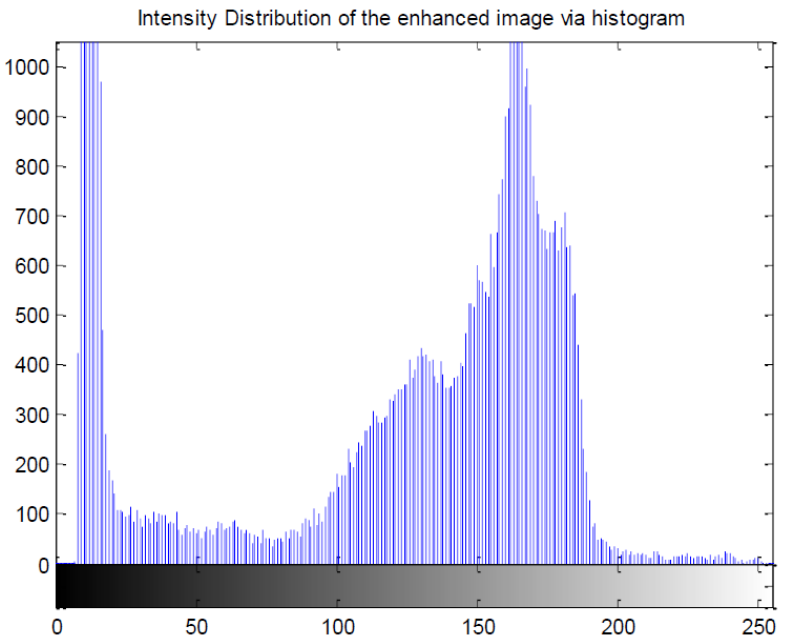

Fig 9. Histogram plot for Fig. 8

\section{B. Noise Removal:}

Digital Images are prone to variety of noise that tends to change the true intensities of the pixel values in the image. With the help of using filters in the image processing schemes a noisy image can be de-noised. Fig 10 shows a grey image free from any sort of noise. In Fig 11 'Salt and Pepper' noise is deliberately added to the image of Fig 10. The resulting figure thus seems blurred. This noise can be removed with the help of a filter. Therefore using 'Median Filter' the 'Salt and Pepper' noise is removed. The resulting image obtained after applying the median filter is shown in Fig 12.

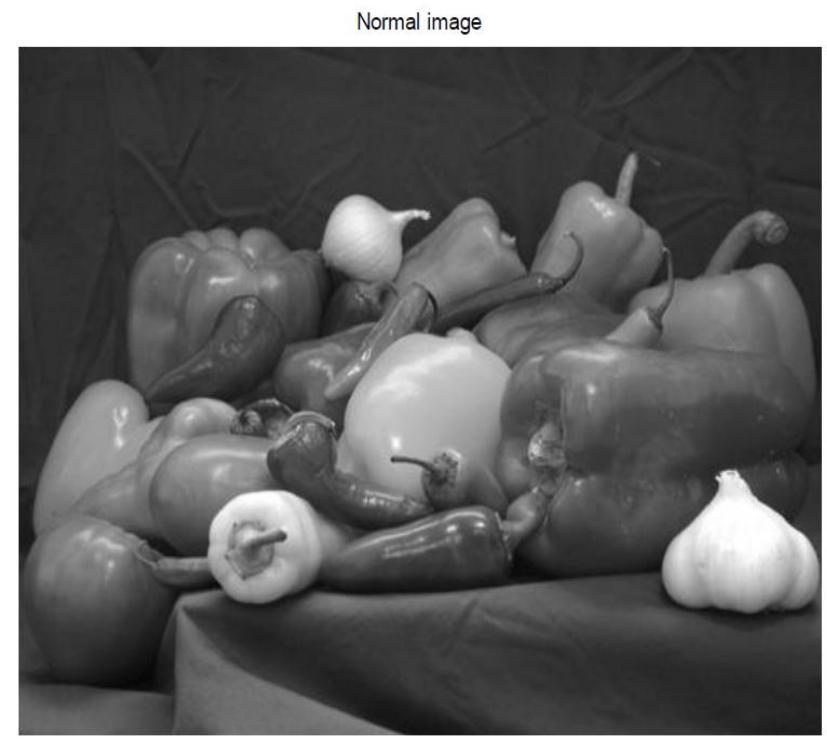

Fig 10. Original image without noise introduction

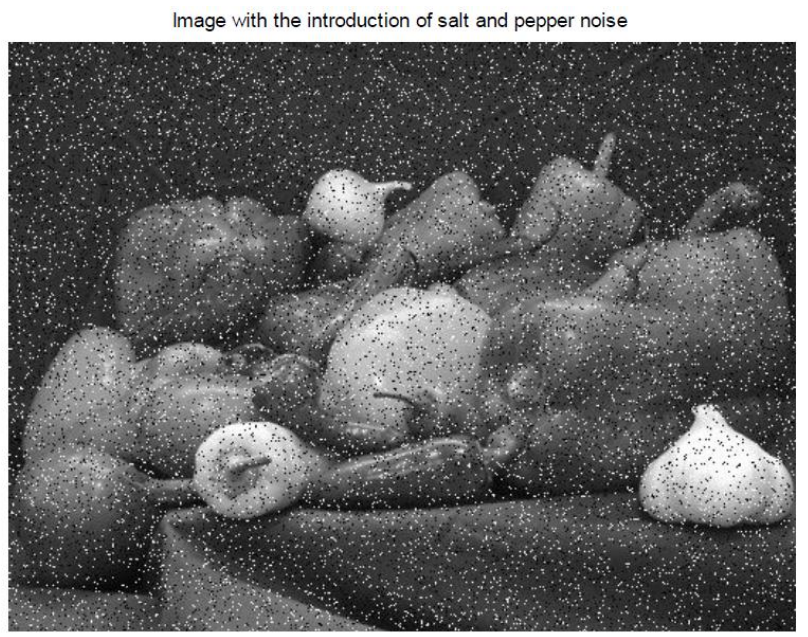

Fig 11. Addition of Salt and Pepper noise to the image of Fig 10. 


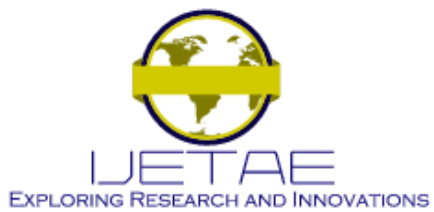

International Journal of Emerging Technology and Advanced Engineering Website: www.ijetae.com (ISSN 2250-2459, ISO 9001:2008 Certified Journal, Volume 4, Issue 6, June 2014)

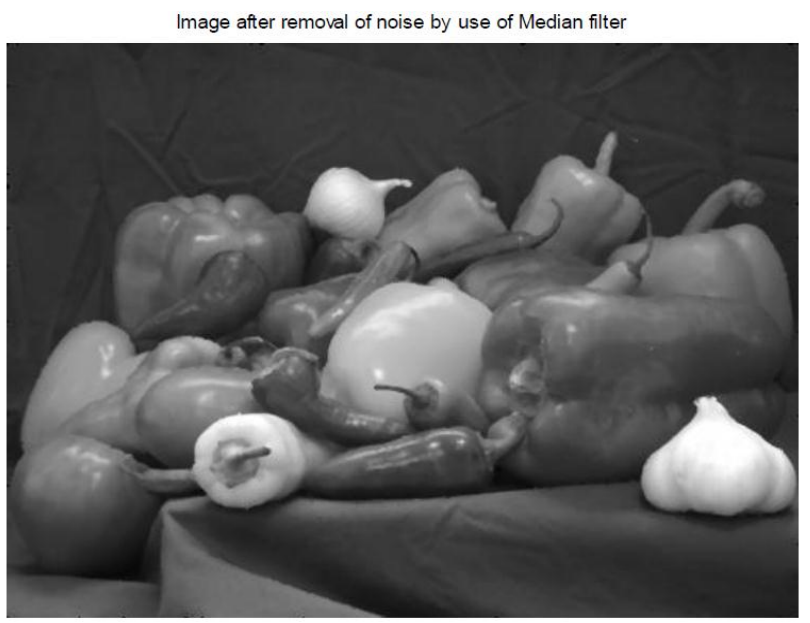

Fig 12. Image after the removal of noise

\section{Image Restoration:}

Image Restoration is the technique of making small modifications to the images. Applications of image restoration range from the removal of an object from a scene to the retouching of a damaged image. Also, the restoration technique can be used to remove deterioration, e.g. a crack in an image or remove and0 add an element to the image. In each case, the goal is to produce a modified image in which the restored region is merged into the image so seamlessly that a typical viewer is not aware that any modification has occurred. To illustrate this two images are taken. The first image i.e. Fig 13 is the image with small amounts of deterioration in it. However after applying the image restoration techniques, the deteriorated image is improved as shown in Fig 14.

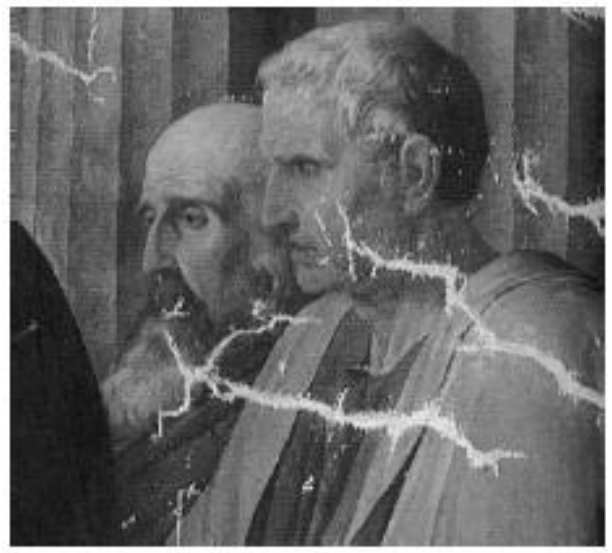

Fig 13. Image with distortions in it

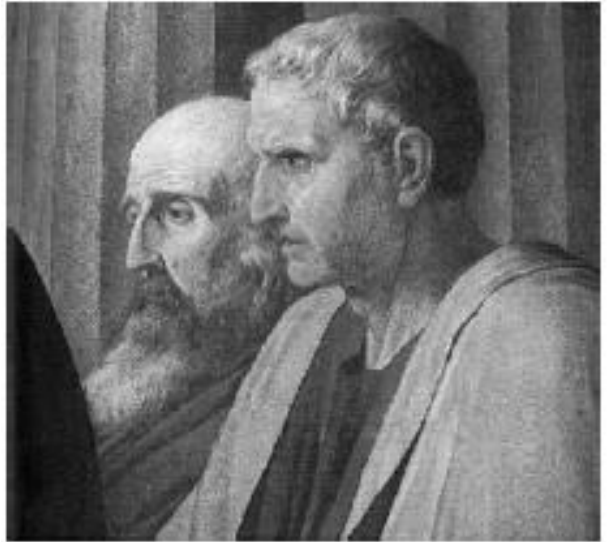

Fig 14 Image after the effects of restoration

\section{Edge Detection:}

Edge Detection identifies object boundaries within images. It works by detecting the discontinuity in the brightness level in the image. Edge detection techniques are used for image segmentation and data extraction in areas such as computer vision, etc. The algorithm used here for edge detection is the 'Canny Edge Detector' algorithm. In this algorithm technique the image is filtered with the derivative of Gaussian. Then the magnitude and orientation is calculated. Two threshold levels are then defined: low and high. The high threshold level is used to start the edge curves while the low threshold level is to continue them. Here also image in Fig 15 is the simple image showing two kids whereas the image in Fig 16 is the image with the edges detected after applying the Canny Edge Detection scheme. 


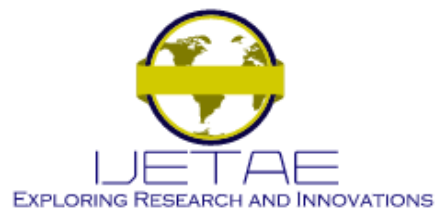

\section{International Journal of Emerging Technology and Advanced Engineering}

Website: www.ijetae.com (ISSN 2250-2459, ISO 9001:2008 Certified Journal, Volume 4, Issue 6, June 2014)

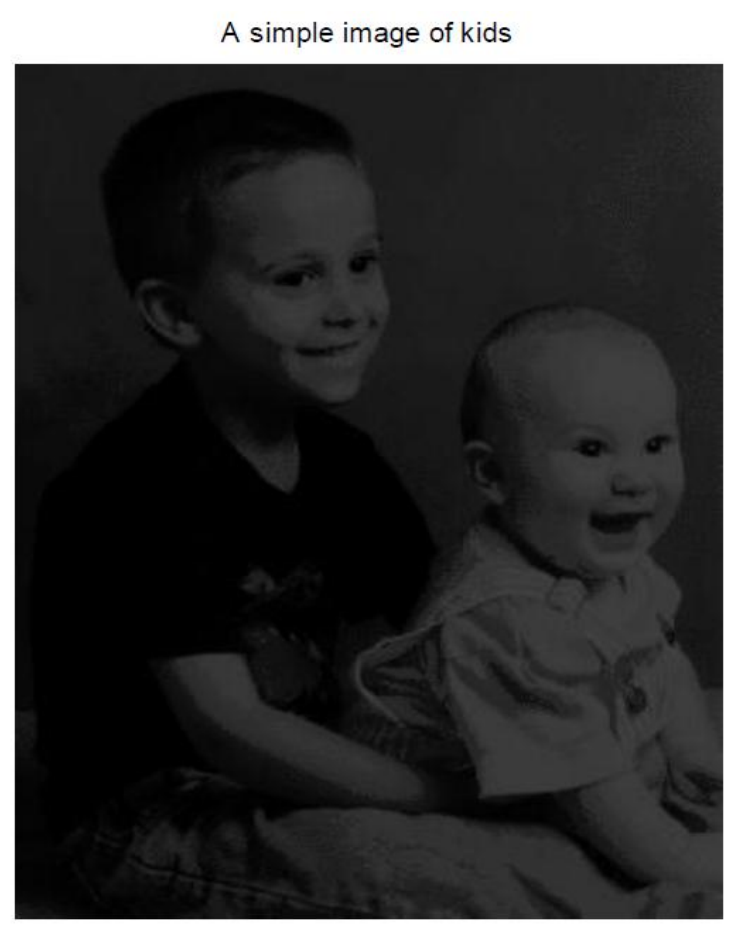

Fig 15. A normal image showing 2 kids

Image with edges detected

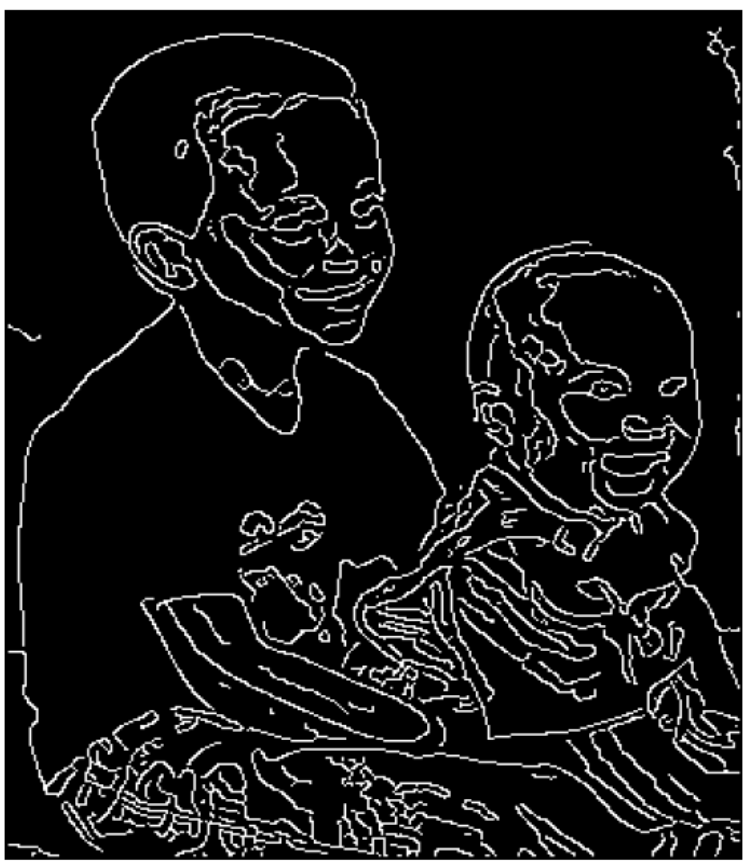

Fig 16. Detection of edges of Fig 15.

\section{E. Image Compression:}

Image Compression is the technique of reducing or elimination of the redundant or irrelevant information from the image. It is one of the most important techniques used image processing. Image compression is almost used everywhere while processing images. For example the image sent by mars rover to the NASA space station is very heavy and large in size. To process the information from the image first it has to be compressed and thus image compression finds its applications. Fig 17 shows an image which is $852 \mathrm{~KB}$ in size but after compression it reduces to 67.2 KB shown in Fig 18.

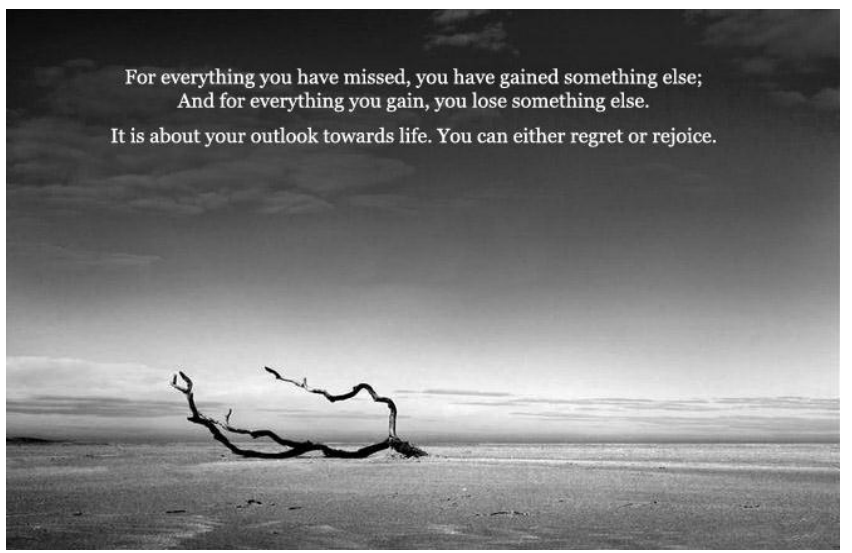

Fig 17 An uncompressed image (852 KB)

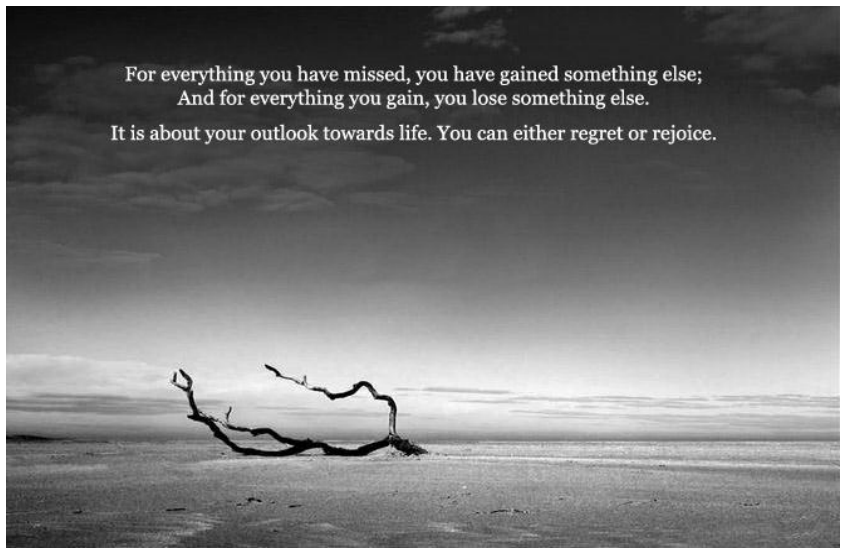

Fig 18 A uncompressed image (67.2 KB)

\section{IMAGE ANALYSIS}

Image Analysis refers to the process of extracting meaningful information from an image. It involves a) Image Segmentation, b) Comparison and Matching between the images, c) Use of image for medical diagnosis. 


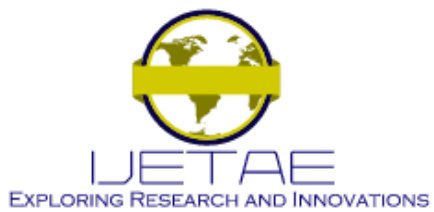

\section{International Journal of Emerging Technology and Advanced Engineering}

Website: www.ijetae.com (ISSN 2250-2459, ISO 9001:2008 Certified Journal, Volume 4, Issue 6, June 2014)

\section{A. Image Segmentation:}

Image Segmentation breaks an image into groups over space and/or time on the basis of different types of properties which are present in an object inside the image. One of the main objectives to perform image segmentation is for easy compression of images. The sequence that is segmented can either be grouped together because they lie on same object or because of some affinity local measure. The segmentation here is done using 'Otsu's Image Segmentation' algorithm. This algorithm technique looks at the histogram of the image and it obtains the segments by looking at the uniform pixel values of the image. Therefore the concern is not the edges but the pixel values inside the segments. Fig 19 shows a normal gray scale image of Saturn and its rings while Fig 20 shows the histogram of the image. Fig 21 is the optimized image after applying the Otsu's algorithm to Fig 19.

\section{A normal gray scale image}

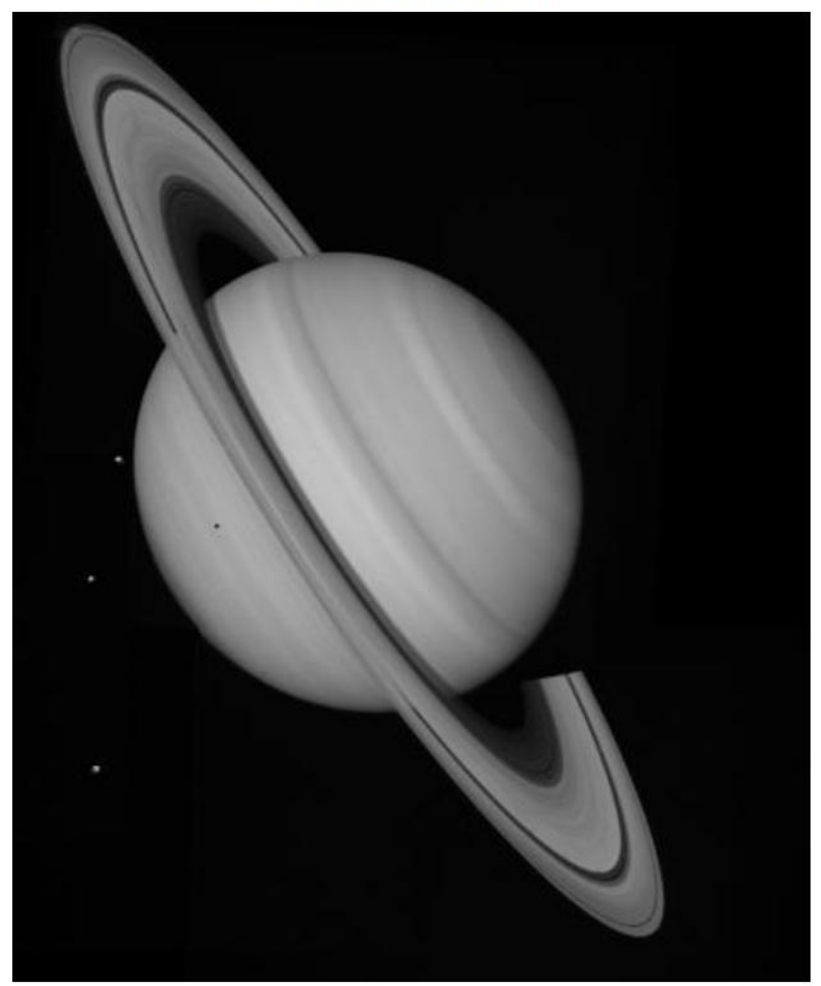

Fig 19. A gray scale image of Saturn

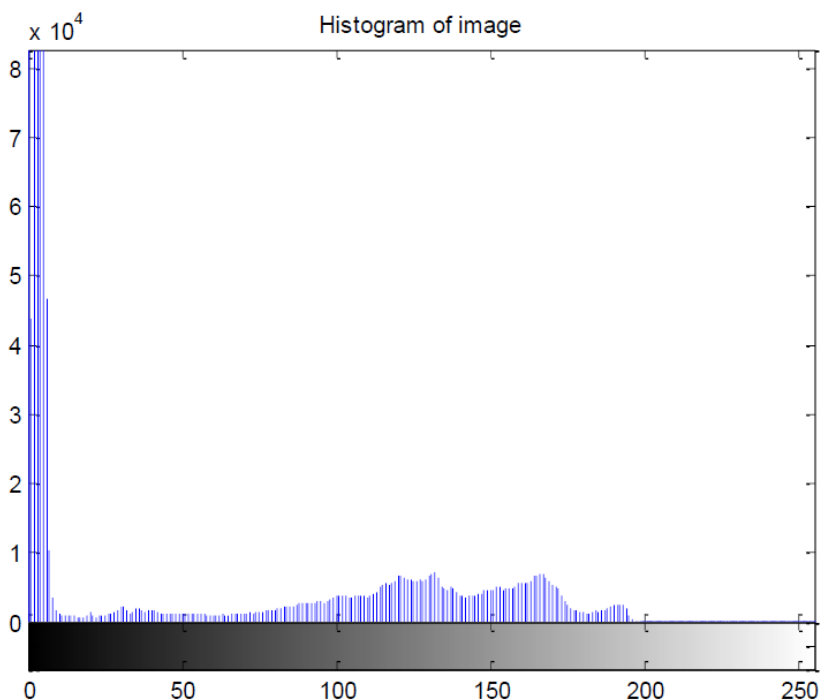

Fig 20. Histogram of image of Fig. 19

Optimized Image with the threshold value

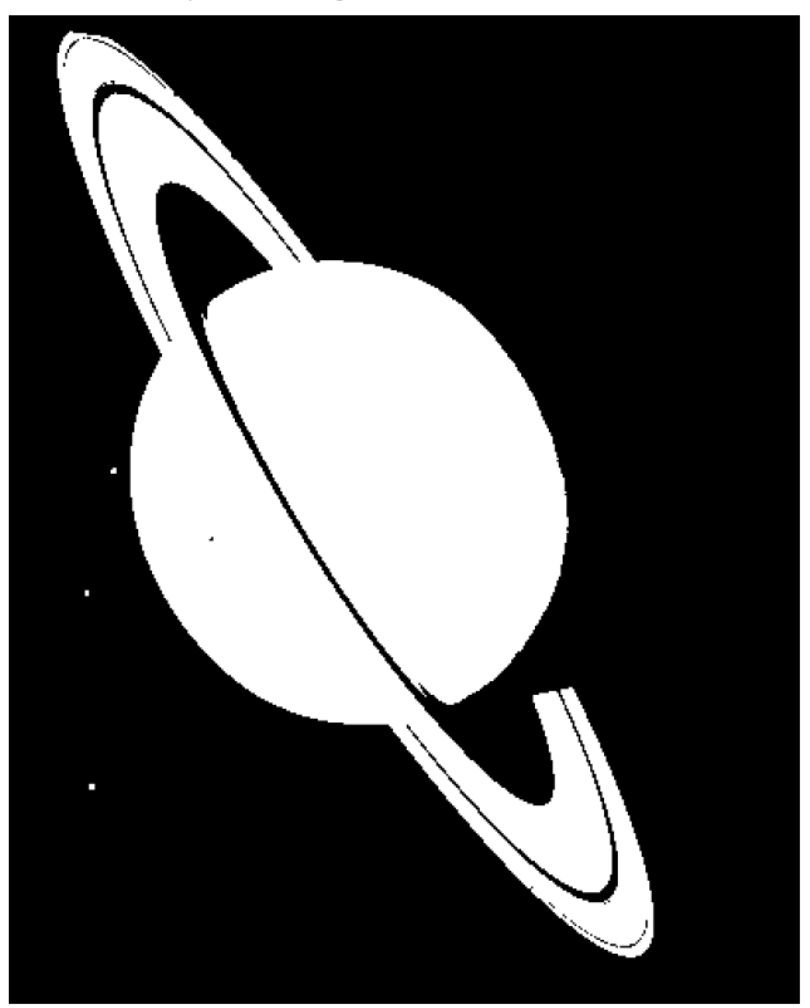

Fig 21. Optimized Image 


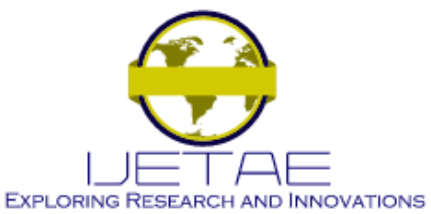

International Journal of Emerging Technology and Advanced Engineering

Website: www.ijetae.com (ISSN 2250-2459, ISO 9001:2008 Certified Journal, Volume 4, Issue 6, June 2014)

\section{B. Feature Detection and Image Matching:}

Image Matching is a technique to obtain correspondence between the images. The basic idea is to detect the feature points also known as the key points and then then to match the feature points in different images. The key points should be able to match corresponding points correctly. Moreover these should be invariant to scale, orientation and even to lightning difference.

\section{Medical Diagnostic using Imaging:}

Medical imaging is a technique in which the interior of the body is represented visually and then those visual representations are used for medical analysis. Medical Imaging is used to reveal the internal body structures as well as to diagnose and treat diseases. One of the most common applications of medical imaging is to study the images of the brain. MRI (Magnetic Resonance Imaging) (Fig 22) is a technique used to study neurological disorders, brain development and structures of brain fiber bundles.

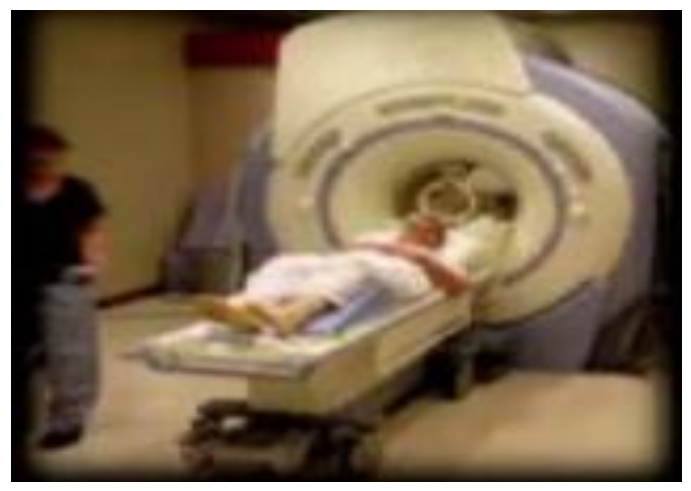

Fig 22. MRI

Deep Brain Stimulation (DBS), Fig 23 is an image analysis scheme used to analyze Parkinson's disease, clinical depression and other neurological problems. Successful DBS surgery is based on the precise placement of DBS electrodes in target structures.

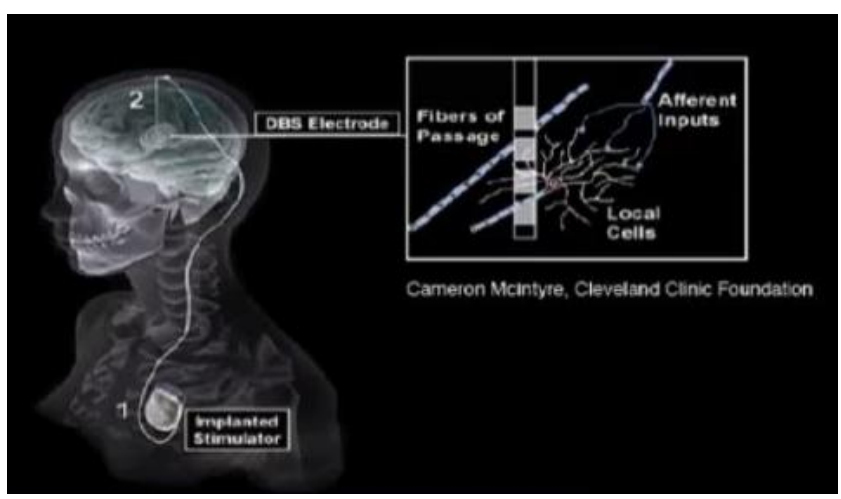

Fig 23. DBS

\section{CONCLUSION}

In this paper various techniques of image processing and analysis has been successfully explained as well as implemented. The simulation has been performed in MATLAB. Two important algorithm techniques 'Canny Edge Detector' and 'Otsu's Image Segmentation' has been explained and results shown.

\section{REFERENCES}

[1] R.C. Gonzalez and R.E. Woods, Digital Image Processing, AddisonWesley, Third edition, 2008.

[2] J.S. Lim, Two Dimensional Signal and Image Processing, Prentice Hall, 1990.

[3] Bovik, Handbook of Image and Video Processing, Academic Press 2000.

[4] N. Netravali and Barry G. Haskell, Digital Pictures, Plenum Press, 1988.

[5] W. K. Pratt, Digital Image Processing, John Wiley and Sons, 1992.

[6] R. C. Gonzalez and P. Wintz, Digital Image Processing, AddisonWesley, 1979.

[7] H. C. Andrews and B. R. Hunt, Digital Image Restoration, PrenticeHall, 1977.

[8] H. C. Andrews, Tutorial and Selected Papers in Digital Image Processing, IEEE Press, 1978.

[9] IEEE Conference on Computer Vision and Pattern Recognition, 1994.

[10] The images used for processing and analysing in the paper are either the built in images in MATLAB or taken from above mentioned references. 